\title{
Alzheimer Disease and Music-Therapy: An Interesting Therapeutic Challenge and Proposal
}

\author{
Aligizakis Eftychios' ${ }^{1}$, Sivaropoulos Nektarios ${ }^{2 *}$, Gryllaki Nikoleta ${ }^{3}$ \\ ${ }^{1}$ Public Health Center of Kandanos, Chania, Greece \\ ${ }^{2}$ Public Health Center of Spili, Rethymno, Greece \\ ${ }^{3}$ Public Health Center of Chania, Chania, Greece \\ Email: aligizak@gmail.com, ^nektsivar@gmail.com,ngrillaki@gmail.com
}

How to cite this paper: Eftychios, A. Nektarios, S. and Nikoleta, G. (2021) Alzheimer Disease and Music-Therapy: An Interesting Therapeutic Challenge and Proposal. Advances in Alzheimer's Disease, 10, 1-18.

https://doi.org/10.4236/aad.2021.101001

Received: March 19, 2021

Accepted: March 28, 2021

Published: March 31, 2021

Copyright $\odot 2021$ by author(s) and Scientific Research Publishing Inc. This work is licensed under the Creative Commons Attribution International License (CC BY 4.0).

http://creativecommons.org/licenses/by/4.0/

\begin{abstract}
Aim: The aim of this study is to highlight the effectiveness of music therapy in Alzheimer's Disease ( $A D)$ and their caregivers. Methods: The biennial 2019 to 2020, 32 patients, with AD (ICD-10), were examined, by a research group composed by a Neurologist, a GP and a Music-psychotherapist. All patients were under pharmaceutical care. The patients' medical record and musical profile was assessed. The answers were provided by the patients themselves or by their tutors. Then, personal or family sessions were organized with the participation of musical instruments. The patients staging and evaluation were made through MMSE. The test was repeated every six months under the Neurologist's supervision. Finally, 31 totally patients succeeded to complete our intervention and to be estimated. Results: The duration of study was totally 30 months, including the preparative stage. At the beginning and end of the sessions we obtained the following data: In a total of 32 patients with $\mathrm{AD}$, initially 3 patients (9.37\%) had Mild AD, 19 patients (59.37\%) had Moderate $\mathrm{AD}, 10$ patients (31.25\%) severe $\mathrm{AD}$, based on the MMSE evaluation. After 30 months, 11 patients had Mild AD (35.48\%), number resulting from the music benefit of cognitive function in patients with moderate AD. 15 patients with Moderate AD (48.38\%) were observed, out of the initial 19 (59.37\%) patients with Moderate $\mathrm{AD}$, a number attributed to the sum of patients who improved from severe $\mathrm{AD}$ and those who were transferred, benefiting from treatment, from Moderate AD disease to Mild AD. Finally 5 patients with severe $\mathrm{AD}$ disease were evaluated (16.12\%), while before the treatment we had 10 patients (31.25\%) with severe AD. Conclusions: Music therapy is a tool to increase the life quality of the participants. The results expected in the treatment of $\mathrm{AD}$ are obtained by means of good collaboration among the research team.
\end{abstract}




\section{Keywords}

Alzheimer Disease Patients, Care Givers, Music-Therapy, Improvement of Cognitive Impairment

\section{Introduction}

Dementia consists a group of symptoms affecting memory, thinking, behavour and social abilities severely enough to mitigate the daily activities of the life. It isn't represent a specific disease, but a mosaic of several diseases may cause dementia. Alzheimer's disease is the most common cause of a progressive dementia in older adults [1].

Different types of Dementia have been established. Usually are progressive and irreversible like Alzheimer Disease, Vascular Dementia, Lewy Body Dementia, FrontoTemporal Dementia and Mixed Dementia, but there are Dementia like conditions that characterized as reversible (infections, immune and metabolic disorders, nutrinonal deficiencies, medications side effects, subdural hematomas, Poisoning, anoxia, Brain tumors, Hydrocephalus). Regarding risk factors of Dementia, have been observed, reversible (Diet and exercise, alcohol use, cardiovascular risk factors, depression, diabetes, smoking, sleep apnea, Nutritional deficits) and unreversible risk factors of the disease (age, family history, Down syndrome) [2].

Dementia symptoms vary depending on the cause, but common signs and symptoms include: Cognitive changes (memory loss, confusion and disorientation, difficulty communicating, with visual and spazial abilities, reasoning, handling complex tasks and planning, difficulty with coordination and motor functions) and psychosocial changes (personality changes, depression, anxiety, inappropriate behavior, Paranoia, agitation, Allucinations) [1] [2].

Dementia and Alzheimer in particular is considered a letal disease due to infections like Pneumonia, Loss of autonomy and inability of selfmanagement and self care tasks, poor nutrition, incapacity of personal safety, strengthening of significant commorbidities for example cardiovascular diseases and finally death. Diagnosing dementia is a challenging matter. It is based on medical history and symptoms and a physical examination. Many times likely, the information are extracted from those concerned, famigliars or caregivers. There is no a single test can diagnose dementia [1].

The diagnosis of Alzheimer's disease is clinical (clinical criteria based on ICD10, DSM-V). Additionally the diagnostic algorithm includes: Cognitive and Neuropsicological tests, Neurological evaluation, Brain Scans, Laboratory test, Psichiatric Evaluation. Usually Brain Scans, CT, EEG or Lumbar puncture are done to exclude other causes. Also during the assessment at least one of the available cognitive tests should be used, like MoCA, GPCOG, Blessed Dementia Information-Memory-Concentration scale (BDS-IMC), MMSE, SLUMS, Mini-Cog and 
MIS cognitive tests [2] [3].

In Dementia, the role of caregivers of people with dementia, which usually consists of family members or caregivers outside the family environment, is extremely important. They usually show aggression, anxiety, frustration, insomnia, while in the areas of life there are changes in their social, professional and family behavior. Caregivers have high levels of depression and negative emotions and a lower sense of satisfaction in their lives, limited social activities, friendly companionship, while reporting a worse level of health, over-the-counter medication and overuse of health service [4].

In the United States, Alzheimer's disease is a huge source of stress for patient caregivers, not only financially but also emotionally or over time. A 2016 study found that those caring for a person with Alzheimer's disease had 28\% less ability to use their income to eat healthily. Another finding is that many family members and friends of people with the disease suffer huge financial bleeding as they channel their savings or pensions to meet the needs of the disabled, sacrificing their sense of personal financial security, which is reinforced. And by offering unpaid, non-remunerative work. One report showed that in 2013 carers spent an average of 21.9 hours a week helping these patients [5].

Regarding therapy of dementia, most types are incurable but with the appropriate medications like Cholinesterase Inhibitors, Memantine and other medications like SSRIs, SNRIs, new generation of Antipsicotics for depression, agitation, sleep disturbances, allucinations, parkinsonism, we can manage and sollevate their symptoms, and temporally improve the cognitive and functional status of the patients [1] [2].

Several dementia symptoms and behavior problems might be treated initially using non drug approaches, such as: Occupational Therapy, Environmental Modifications, misures to Simplifying the tasks. Additionaly we can suggest other alternative therapies, that may help reduce agitation and promote relaxation in people with Demenzia: Music Therapy, Light exercise, watching video of family members, Pet therapy, Aroma and Massage therapy and finally Art therapy [2].

In this article, our research activity focuses mainly on alternative therapeutic interventions and especially on the use of Music Therapy as a mean of reducing the mental and behavioral symptoms of demented patients, but secondly we examine whether the potential improvement of patients' condition through music therapy and the impact to their overburdened caregivers.

Music therapy interventions are widely used as a potentially non-pharmacological treatment for Alzheimer's disease to improve symptoms in perception and behavior. Despite the widespread use of such therapies, data on their effectiveness remain mixed in the literature.

Music is one of the most ancient healing tools. According to Pythagoras, musical proportions are similar to mental ones and therefore change with the help of music [6] [7].

In that case when the balance of opposites in the soul is disturbed, mental ill- 
nesses arise, where music has the power to restore the disturbed soul to world harmonies and to the harmony between the universe, soul and music.

Plato argued that music was not given to man to entertain his senses, but to soothe the sufferings of his soul and body [8] [9] [10].

Aristotle emphasized the emotional quality of music, its effect on the feelings and emotions of people [11] [12] [13].

Tibetan monks had realized that chanting simple sounds could change their state of consciousness and increase their sense of well-being.

In the United States, music therapy was first adopted during World War I to assist soldiers in veterans' hospitals. The American Music Therapy Association (AMTA) was founded in 1998 as a result of the merger of the American Music Therapy Association (founded in 1971) and the National Music Therapy Association (1950). Its mission is to raise public awareness of the benefits of music therapy and increase access to quality music therapy services [14].

Modern music therapists argue that the disease occurs when the various types of energy associated with the mind, body and spirit vibrate at the wrong frequencies [15].

Music therapists work with people with dementia, Parkinson's disease, postoperative and chronic pain from conditions such as cancer, osteoarthritis, and during neurological and physical rehabilitation [16] [17]. Today, in fact, there are centers in which women are prepared through music before, during and after childbirth [18].

Several therapeutic techniques work for small groups that include older people with Alzheimer's disease and their caregivers who are usually members of the same family [19] [20].

\section{Aim}

The purpose of the retrospective study is to highlight the effectiveness of music therapy in patients with Alzheimer's disease and the potential benefits to their caregivers.

\section{Materials and Methods}

During biennial 2019-2020, 32 patients with Alzheimer's disease (ICD-10, criteria) were examined, 17 women and 15 men (54 to 81 years old), with a mean age of 67.5 years. It is noteworthy that during our research, an Alzheimer's disease patient, male, 73 years old, belonging to our initial sample of 32 patients, died due to Pneumonia, thus 31 patients completed our therapeutic framework. The research team that conducted the study included a neurologist, a general practitioner, and a music psychotherapist-psychologist. All patients received medication from a neurologist (antidepressants, Rivastigmine or Donepezil or a combination thereof, 6 months before and throughout the study.

All the patients who participated in the research came from the neurologist, who urged patients and caregivers to start music therapy sessions. The selection 
of participants was made randomly regardless of life, social, educational level and concomitant diseases. The competent $\mathrm{AD}$ patients or caregivers themselves initially filled out the informed consent form with whatever it entails.

The examiners obtained the Medical and Social history of the patients, as well as, their music profile (their musical preferences from childhood to the time they became ill). The detailed completion of the music profile included:

1) Identity card (general details of the examinee) and the stage of the disease to which the patient corresponds.

2) Musical Receptivity (general musical receptivity, receptivity to certain types of music, receptivity to certain musical sounds and to certain types of instruments).

3) The view of the healed regarding the therapeutic use of Music.

4) Sound Environment (such as family, ancestors, previous personal experiences, modern sound environment),

5) The Music Therapy Questionnaire (by R. Benenjon with 17 questions).

6) Discussion about music culture.

Then came the music therapy sessions with the participation of various musical instruments (piano, maracas, scrapers, bogo, drums and claps). The sessions were held at the level of group and individual meetings. The frequency of these meetings was three times per week either in an individual session or in a group session lasting no longer than 1 hour.

The parts of the music therapy session were as follows:

1) Listening to Music

2) Song

3) Improvisation

4) Listening to Music and Talking.

In group sessions the music therapist used the piano and each patient one of the other musical instruments of his choice. The therapist chose a musical theme that was as close as possible to the musical profiles of those present with a sample of various musical excerpts (duration 3 - 5 minutes each with a maximum number of 10 music excerpts). e.g. a descriptive work, a rhythmic work, a melodic work, noises from a workshop, a contemporary musical theme.

An interactive dialogue began: The music therapist played various chords on the piano and one of the patients responded by playing the musical instrument of his choice.

The same process was repeated with the answer of two, three and finally all together with the meeting. The caregivers actively participated throughout the session, giving rhythm with the clapping of the hands. Rhythm was the link that musically bridged patients (musical experiences from the past) with their caregivers (their representatives in the present).

In the individual sessions, the music therapist, utilizing the music profile of the patient, chose a song contemporary with the productive period of the patient. The therapist played and sang, stopped, and continued to be interpreted (singing or, if he could not, chanting) by the patient. They both stopped and a 


\begin{tabular}{|c|c|c|c|}
\hline Score & $\begin{array}{l}\text { Degree of } \\
\text { Impairment }\end{array}$ & $\begin{array}{l}\text { Formal Psychometric } \\
\text { Assessment }\end{array}$ & Day-to-Day Functioning \\
\hline $25-30$ & $\begin{array}{c}\text { Questionably } \\
\text { significant }\end{array}$ & $\begin{array}{l}\text { If clinical signs of cognitive impairment } \\
\text { are present, formal assessment of } \\
\text { cognition may be valuable. }\end{array}$ & $\begin{array}{l}\text { May have clinically significant but } \\
\text { mild deficits. Likely to affect only } \\
\text { most demanding activities of daily } \\
\text { living. }\end{array}$ \\
\hline $20-25$ & Mild & $\begin{array}{l}\text { Formal assessment may be helpful to } \\
\text { better determine pattern and extent of } \\
\text { deficits. }\end{array}$ & $\begin{array}{l}\text { Significant effect. May require } \\
\text { some supervision, support and } \\
\text { assistance. }\end{array}$ \\
\hline $10-20$ & Moderate & $\begin{array}{l}\text { Formal assessment may be helpful if } \\
\text { there are specific clinical indications. }\end{array}$ & $\begin{array}{l}\text { Clear impairment. May require 24- } \\
\text { hour supervision. }\end{array}$ \\
\hline $0-10$ & Severe & Patient not likely to be testable. & $\begin{array}{l}\text { Marked impairment. Likely to } \\
\text { require 24-hour supervision and } \\
\text { assistance with ADL. }\end{array}$ \\
\hline
\end{tabular}

Figure 1. Illustration of the interpretation of MMSE score results. Note: Figure 1, depicts the interpretation of the MMSE scale results and their meanings in the severity staging of Demenzia. Folstein MF, Folstein SE, McHugh PR: "Mini-mental state: A practical method for grading the cognitive state of patients for the clinician." J Psychiatr Res $1975 ; 12: 189-198[21]$.

discussion ensued. The music therapist asked the patient if the song reminded him of anything, his thoughts, if it caused him positive or negative emotions (attempt to recall).

The classification and evaluation of the clinical course of patients was based on the Mini Mental State Examination Questionnaire [21] (Mental State Test that examines the following parameters: orientation, engraving, attention and arithmetic, recall, language), which is characterized by the following calibrated scale which classifies patients with different levels of disease severity as indicated in Figure 1 [21]. The above Mini Mental Test was repeated every six months under the supervision of the neurologist of our team. Regarding the Music therapy of AD patients and the impact to the caregivers, we considered if interpersonal relationships were improved and emotional ties were strengthened as well as the daily interaction in practical matters of caregivers with patients. The main caregiver for each patient was examined, a total of 31 caregivers, through a structured interview.

\section{Results}

The duration of follow-up of the patients was biennial. At the beginning and end of the sessions we obtained the following data displayed in Table 1 and Graph 1 and Graph 2. In a total of 32 patients with $\mathrm{AD}$, initially 3 patients (9.37\%) had mild mental impairment, 19 patients (59.37\%) had moderate mental impairment, 10 patients (31.25\%) severe mental impairment, based on the MSE evaluation and staging scale of the disease. After 30 months, at the completion and completion of the study, a total of 31 patients, if one patient died in the meantime due to pneumonia, therefore cannot be evaluated, not completing the program, 11 patients had mild mental illness (35.48\%), number resulting from the benefit of improving cognitive function in patients with moderate AD. Fifteen 
Table 1. Illustration of follow up AD patients results in absolute numbers, before and after music-therapy intervention.

\begin{tabular}{cccc}
\hline $\begin{array}{c}\text { COGNITIVE } \\
\text { LEVEL }\end{array}$ & $\begin{array}{c}\text { Severe AD } \\
\text { Cognitive Impairment } \\
\text { (MMSE Score: 1 - 10) }\end{array}$ & $\begin{array}{c}\text { Moderate AD } \\
\text { Cognitive Impairment } \\
\text { (MMSE Score: 11 - 20) }\end{array}$ & $\begin{array}{c}\text { Mild AD Cognitive } \\
\text { Impairment } \\
\text { (MMSE Score: 21 - 25) }\end{array}$ \\
\hline $\begin{array}{c}\text { THERAPY } \\
\text { BEFORE THERAPY } \\
\text { Men }\end{array}$ & 4 & 10 & 1 \\
Women & 6 & 9 & 2 \\
AFTER THERAPY & $2\left({ }^{*} 1\right)$ & 7 & 5 \\
Men & 3 & 8 & 6 \\
Women & & & \\
\hline
\end{tabular}

Note. Table 1, shows, final follow up patients AD data, specifically expressed as absolute numbers of patients belonging to different stages of $\mathrm{AD}$ severity before and after music therapy intervention. $\left({ }^{*} 1\right)$ Patient who died.

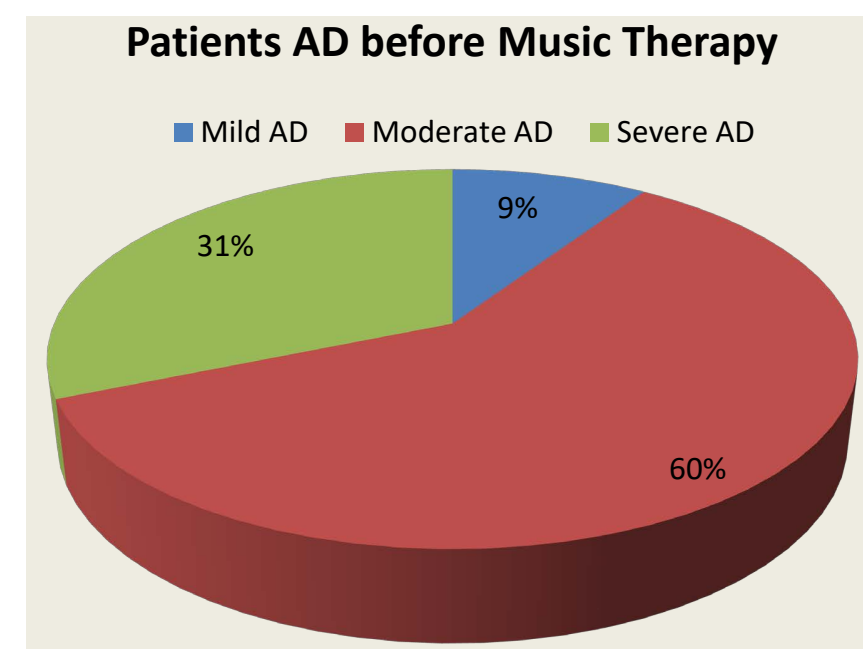

Graph 1. Patients (AD) before starting music therapy.

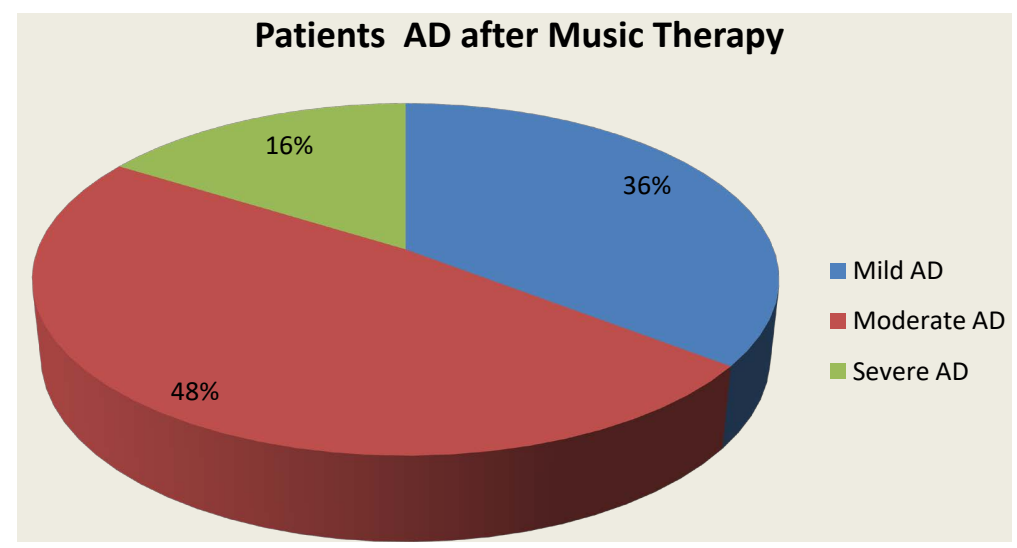

Graph 2. Patients (AD) after the Music-Therapy therapeutic intervention.

patients with moderate mental retardation (48.38\%) were observed, out of the 
initial 19 (59.37\%) patients with moderate disease, a number attributed to the sum of patients who improved from severe disease and those who were transferred, benefiting from treatment, from moderate $\mathrm{AD}$ disease to mild $\mathrm{AD}$ mental impairment based on the MMSE scale.

Finally, 5 patients with severe AD disease were evaluated (16.12\%), while before the treatment we had 10 patients (31.25\%) with severe mental impairment, while as mentioned above, one patient with severe AD disease, a 73-year-old man died before completion the study. Regarding the effects of the treatment on caregivers who were interviewed in person, there was an improvement in their daily interaction, a reduction in their stress, and a strengthening of their emotional bonds with patients. We therefore believe that caregivers, indeed as important members of the cohesive patient-caregiver, indirectly benefited from our intervention.

\section{Statistics}

According to Graph 1 and Graph 2 the patients with severe mental retardation showed a significant change (reduction of about 50\%), as some benefited from the treatment and moved to the stage of Moderate $\mathrm{AD}$, while among these patients belongs the patient who died. Patients with mild AD showed an increasing trend in the percentage of patients at this stage (an increase of 27\%) which, however, is due to improved mental function of patients with moderate $\mathrm{AD}$, after music therapy, who transition to this stage.

However, the percentage change of patients with moderate mental retardation (Moderate $\mathrm{AD}$ ) is also remarkable, where a decrease in the percentage of patients was observed at this stage, after the music therapy of $12 \%$, since they presented a significant benefit from music therapy.

\section{Discussion}

Alzheimer's disease is a degenerative disease of the brain that causes progressive impairment of higher mental functions with major social and economic implications. It results in the progressive degeneration of memory, thought and behavior change. Its name is due to the German physician Alois Alzheimer where he described the characteristics of the disease in 1907. Worldwide, around 50 million people have dementia, and there are nearly 10 million new cases every year. Alzheimer's disease is the most common form of dementia and may contribute to $60 \%-70 \%$ of cases. Dementia is one of the major causes of disability and dependency among older people worldwide [1] [21].

The disease usually occurs in people over the age of 65 , while the occurrence of the disease in the ages of 40 to 50 years is not excluded. Until recently, the theory was that dementia in people over the age of 65 was due to atherosclerosis of the blood vessels in the brain called "senile dementia." This attitude began to change in the 1970s [1] [21].

The etiology of the disease has not yet been clarified but both genetic and en- 
vironmental factors are to blame [22] [23] [24].

There is no conclusive evidence that any of the proposed treatments for Alzheimer's disease such as e.g. brain vasodilators such as Naftidrofuril or large doses of vitamins B, C and E etc.) have some particular beneficial effect [25] [26] [27] [28] [29].

Pharmacotherapy aims to improve perception and alleviate behavioral symptoms; however the various drugs provide only moderate benefits to patients, according to some studies [30] [31]. (Cholinesterase antagonists (Rivastigmine, Donepezil, Galantamine) and Memantine may stabilize or delay disease progression [32].

Especially with regard to the newest Memantine, its administration seems to be beneficial in terms of cognitive ability at all stages of the disease, especially in patients with moderate mental impairment [33].

SSRIs even in the absence of depression have been shown to delay the progression of early mental decline in Alzheimer's. This is probably due to the action of SSRIs on the production of $\beta$-amyloid precursor protein, the accumulation of which is a histopathological basis of the disease. Thus, although SSRIs are less effective in treating Alzheimer's-related depression, they may have therapeutic potential in treating and delaying Alzheimer's, especially if treatment is started early [34].

Risperidone and SSRIs in a meta-analysis have been shown to be effective in anxiety caused by Alzheimer's disease and its findings do not support haloperidol administration due to reduced efficacy [35].

Music therapy is a flexible and accessible tool and can be used on patients in a variety of ways. Raglio and Oasi at 2015, described 3 approaches for clinical use: Music therapy, music listening and music-based interventions.

Music therapy according to the Canadian Association of Music Therapists is "The method by which certified professionals use music intentionally within therapeutic relationships with patients to promote growth, health and wellness. Music therapy involves the crucial factor of client/therapist interaction through an empirical model and can include active (improvisation, song, clapping, dancing) or passive (active listening to music to recognize the emotional elements it contains) techniques.

Music listening approaches include therapist-to-patient playlist creation that can be individualized or selected by the therapist.

Recent literature suggests that personalized choices are more beneficial in $\mathrm{Alz}$ heimer's disease by improving autobiographical memory, information proved by several studies [35] [36] [37] [38].

Generalized Musical Interventions include the use of music without a therapist in order to improve the well-being of the patient. These methods can also use active or passive protocols. "Listening to music is used to evoke expression, memories or to enhance relaxation," as reported by a study [39].

The international literature often overlaps confirms and extends the conclu- 
sions of our study. The general conclusion is that people with dementia typically respond to music for a variety of reasons. First of all, there is evidence that the memory of music can remain intact in people with $\mathrm{AD}$ even when they experience a sharp decline in perception like mentioned in a survey [40]. This is believed to be due to the fact that musical neural networks are different from traditional temporal memory-related temples [41] [42]. Which are maintained until the advanced stages of the disease [43].

Music activates a wider network in the brain and not just a "music area". More specifically, listening to familiar music (such as popular traditional music, children's songs, pop of the time), the music memory retrieval included areas inside and outside the temporal lobe, as well as frontal and parietal sections like confirmed by other studies [41] [42] [43]. These diffuse networks may allow the rescue of music functions.

Also, in a survey, Jacobsen [43], used PET techniques to determine the extent to which music listening areas are affected by Alzheimer's histopathology such as amyloid accumulation and glucose metabolism relative to the rest of the brain and found that these areas were less pathological. The ability of people to remember music makes it a unique stimulus that effectively activates people with Alzheimer's.

Statistical analyzes also reveal that overall the effect of music and music therapy in particular is significant, although the magnitude of the effect is not consistent in all studies [44].

Several literature reviews have documented the beneficial effects of music interventions on a number of clinical populations and four of them have specifically focused on the use of music activities with people with dementia [45][51].

Studies have also been done on Alzheimer's disease. For example, research on music therapy in people in nursing homes and their family health found that music therapy increased visit satisfaction significantly. He also found that the highest participation appeared in the song and rhythm experience [52].

It is well known that patients with Alzheimer's disease can often suffer from depression. Research has shown that successful participation in music can relieve depression, frustration and feelings of failure [52].

In addition, it seems that the stimulus of rhythm, harmony, the well-known melody encourages the elderly person to move towards music. Music therapy in either an individual or group setting can provide stimulation and sensory stimulation, maintain existing potential, and improve quality of life [53].

Most studies have reported that the effects of music are effective in reducing a range of provocative behaviors including agitation/aggression, agitation, abstract thinking, repetitive voices, irritability, hallucinations and anxiety [54][66].

Researchers have suggested that playing even recorded music (selected ac- 
cording to individual preferences) made environmental noise familiar and predictable, and provided a link to positive memories from the past that evoked soothing emotions in the present [66] [67].

Music increases the effects of orientation, memory recall, levels of commitment and participation and social behavior [53] [68]-[73].

Also playing recorded music creates an atmosphere of relaxation [70]. It is noteworthy that the structure of the session and the therapeutic model of the musical activity facilitated participation and social behavior [70]. Music therapists recorded music as a veil that covered the frightening and unknown noise in the environment [71].

Of course, there are some objections regarding the effectiveness of music therapy. In particular, studies have shown that although music significantly increased relaxation levels, it did not significantly reduce the frequency of aggressive behaviors [73].

Researchers also found no differences in the levels of stimulation and agitation comparing conditions of absence of music and music. They justified this fact because the music in their research was not selected as a result of the composition of the individual preferences of the participants [58].

Other music therapists found that participants showed significantly more appropriate reactions to exercises with exercises rather than music therapy with song [74] [75].

A recent Spanish study showed that for the family and caregivers of Alzheimer's patients they observed a 50\% improvement in patients' social behavior [76].

A review of the relevant literature of the period 2008-2018 that compared the various music therapy approaches concluded that regardless of the technique used, the formats that included a personalized selection of music, had the best results [77].

Listening to music can also be a relaxing technique with long-term benefits for patients, while active music therapy may be able to engage participants in social interaction causing immediate benefits. The findings of this publication suggest that music therapy can be used in a variety of ways to improve behavior and perception in these patients [77].

Regardless of the mixed results in the literature, many researchers and clinicians suggest that music should be used in a clinical setting like referred by different studies [78] [79].

\section{Conclusions}

In the present study, the main parts where we noticed that Music Therapy helped with Alzheimer's disease are the following:

1) The stage of the disease to which our patient corresponds and the MiniMental State Examination (MMSE).

2) The ability to find words and express simple ideas. The cultivation of recent 
memory in terms of knowledge in materials e.g. food preparation, memory recall, which contributes to patient satisfaction.

3) Increasing the speed of detection through the eyes and hearing in terms of capturing and processing incoming information.

4) Positive mood swings and emotional intimacy when spouses and families share their creative music experience. Reducing stress, reducing depressive behavior. Reduce anxiety and stress for caregivers.

The effect of music therapy on Alzheimer's patients was recorded as a result of long-term observation from different sources (caregivers, general practitioner, psychologist-music therapist) in the effort to synthesize different addicts and non-addicts.

The most objective control test was the Mini Mental state examination performed under the supervision of a neurologist.

The weaknesses of the study include the creation of an emotional relationship between the research team and the treatment team that reduces the reliability of the observation, the inability to record with a reliable method the effect of music therapy on behavior and emotion, and the absence of a group of patients receiving medication. For a period of time without participating in music therapy sessions as a witness.

Music therapy is a very important tool in improving the quality of life of both patients with chronic diseases and their caregivers, thus fulfilling its goalspurposes on a mental, physical, emotional and social level.

The desired results in the treatment of Alzheimer's disease are due to the good cooperation of the research-treatment team. It is found that music therapy does not cure Alzheimer's disease but improves the quality of life and acts as an important means of communication.

\section{Author Contributions}

All authors have contributed to the work, agree with the presented findings, and that the work has not been published before nor is being considered for publication in another journal.

\section{Acknowledgements}

This review is intended to assist the scientific community in its efforts to address the extremely complicate Alzheimer disease and to seek the efficiency and the benefit of alternative therapeutic approaches as Music-therapy, as adjuvant therapy. We express our sincere, cordial recognition, respect, admiration and gratitude to the dedication, abnegation and sacrifice of all the health stuff, scientists, pharmacists and pharmaceutical companies, public service workers, global health decision making bodies, governments and all the various frontline workers who contribute daily to assist $\mathrm{AD}$ patients maintain a good quality of life and live with pride and dignity. 


\section{Statement}

An unauthorized version of the Greek MMSE was used by the study team without permission, but we rectified the Permission. The MMSE is a copyrighted instrument and may not be used or reproduced in whole or in part, in any form or language, or by any means without written permission of PAR.

(https://www.parinc.com).

\section{Compliance with Ethical Standards}

\section{Ethical Approval/Informed}

Procedures involving experiments on human subjects are done in accord with the ethical standards of the Committee on Human Experimentation of the institution in which the experiments were done or in accord with the Helsinki Declaration of 1975. Authors declare no violation of ethical standards. Patients, Famigliars and Caregivers themselves, agreed, with their fully informed and autonomy will, to participate to the research while the authors, applied the ethical and appropriate scientifically informed consent standards.

\section{Conflicts of Interest}

Authors report none.

\section{References}

[1] World Health Organization (2021) Dementia. https://www.who.int/news-room/fact-sheets/detail/dementia

[2] Mayo Clinic (2021) Dementia. https://www.mayoclinic.org/diseases-conditions/dementia/symptomscauses/syc-20 $\underline{352013}$

[3] Atri, A. (2019) The Alzheimer's Disease Clinical Spectrum: Diagnosis and Management. Medical Clinics of North America, 103, 263-293. https://doi.org/10.1016/j.mcna.2018.10.009

[4] William, H., Levine, E., Brown, L., et al. (1987) Psychosocial, Social and Health Consequences of Caring for a Relative with Senile Dementia. Journal of American Geriatrics Society, 35, 405-411. https://doi.org/10.1111/j.1532-5415.1987.tb04661.x

[5] Grabher, B.J. (2018) Effects of Alzheimer Disease on Patients and Their Family. Journal of Nuclear Medicine Technology, 46, 335-340. https://doi.org/10.2967/jnmt.118.218057

[6] Sakellarion, G. (1962) Pythagoras: The Century Master. Ideotheatron Press, Athens.

[7] O’ Oliver, F. (1995) The Golden Verse of PYTHAGORAS. Solar Press, New York.

[8] Francis, M.C. (1945) Plato: The Republic of Plato. Oxford University Press, New York

[9] Kraut, R. (1992) Cambridge Companion to Plato. Cambridge Press, London. https://doi.org/10.1017/CCOL0521430186

[10] Vlastos, G. (1981) Platonic Studies. 2nd Edition, Princeton, London.

[11] Gerald, F.E. (1967) Aristotle, Poetics. University of Michigan Press, Ann Arbor.

[12] John, H. (1947) Aristotle: The “Art” of Rhetoric. Classical Library, Loeb. 
[13] Else, G.F. (1963) Aristotle's Poetics: The Argument. Harvard University Press, Cambridge.

[14] AMTA: American Music Therapy Association, Silver Spring, Maryland USA.

[15] Wheeler, B. (1981) The Relationship between Music Therapy and Theories of Psychotherapy. Music Therapy. The Journal of the American Association for Music Therapy, 1, 9-16. https://doi.org/10.1093/mt/1.1.9

[16] Ridder, H.M. (2002) Singing in Individual Music Therapy with Elderly Persons Suffering from Dementia. Music Their World.

[17] Griffith, R.W. (2001) Music Making Helps Parkinson's Patients. Health Age, 1, 3-5.

[18] Steele, P.H. (1988) Children's Use of Music Therapy. In Music Therapy One Day Conference: Music and the "Cycle of Life".

[19] Woodcock, J. (1987) Towards Group Analytic Music Therapy. Journal of British Music Therapy, 1, 16-22. https://doi.org/10.1177/135945758700100105

[20] Brotons, M. and Marti, P. (2003) Music Therapy with Alzheimer's Patients and Their Family Caregivers: A Pilot Project. Journal of Music Therapy, 40, 138-150. https://doi.org/10.1093/jmt/40.2.138

[21] Folstein, M.F., Folstein, S.E. and McHugh, P.R. (1975) Mini-Mental State: A Practical Method for Grading the Cognitive State of Patients for the Clinician. Journal of Psychiatric Research, 12,189-198. https://doi.org/10.1016/0022-3956(75)90026-6

[22] Adams, R.D. and Victor, M. (2000) Principles of Neurology. 7th Edition, McGrawHill Professional, Boston.

[23] Bradley, W.G., Daroff R.B., Fenichel, G.M., et al. (2004) Pocket Companion to Neurology in Clinical Practice. 4th Edition, Elsevier, Butterworth-Heinemann.

[24] Beers, M.H. and Berkow, R.D. (2018) The Merck Manual of Diagnosis and Therapy. 20th Edition, Merck Editor, Kenilworth.

[25] Zhang, D.M., Ye, J.X., Mu, J.S., et al. (2017) Efficacy of Vitamin B Supplementation on Cognition in Elderly Patients with Cognitive-Related Diseases. Journal of Geriatric Psychiatry and Neurology, 30, 50-59.

https://doi.org/10.1177/0891988716673466

[26] Wang, W., Li, J., Zhang, H., et al. (2021) Effects of Vitamin E Supplementation on the Risk and Progression of AD: A Systematic Review and Meta-Analysis. Nutritional Neuroscience, 24, 13-22. https://doi.org/10.1080/1028415X.2019.1585506

[27] D’Cunha, N.M., Georgousopoulos, E.N., Kellett, J., et al. (2018) Effect of Long-Term Nutraceutical and Dietary Supplement Use on Cognition in the Elderly: A 10-Year Systematic Review of Randomized Controlled Trials. British Journal of Nutrition, 119, 280-298. https://doi.org/10.1017/S0007114517003452

[28] Lu, D., Song, H., Hao, Z., et al. (2011) Naftidrofuril for Dementia. Cochrane Database of Systematic Reviews, No. 12, CD002955.

https://doi.org/10.1002/14651858.CD002955.pub4

[29] McCleery, J., Abraham, R.P., Denton, D.A., et al. (2018) Vitamin and Mineral Supplementation for Preventing Dementia or Delaying Cognitive Decline in People with Mild Cognitive Impairment. Cochrane Database of Systematic Reviews, 11, CD011905. https://doi.org/10.1002/14651858.CD011905.pub2

[30] Lanctot, L.K., Hermann, N., Yau, K.K., et al. (2003) Efficacy and Safety of Cholinesterase Inhibitors in Alzheimer's Disease: A Meta-Analysis. CMAJ, 169, 557-564.

[31] Casey, A.D., Antimisiaris, D., et al. (2010) Drugs for Alzheimer's Disease: Are They 
Effective? $P \& T, 35,208-211$.

[32] Tan, C.C., Yu, J.T., Wang, H.F., et al. (2014) Efficacy and Safety of Donepezil, Galantamine, Rivastigmine, and Memantine for the Treatment of Alzheimer's Disease: A Systematic Review and Meta-Analysis. Journal of Alzheimer's Disease, 41, 615-631. https://doi.org/10.3233/JAD-132690

[33] Reisberg, B., Doody, R., Stoffler, A., et al. (2003) Memantine in Moderate-to-Severe Alzheimer's Disease. The New England Journal of Medicine, 348, 1333-1341. https://doi.org/10.1056/NEJMoa013128

[34] Elsworthy, R.J. and Aldred, S. (2019) Depression in Alzheimer's Disease: An Alternative Role for Selective Serotonin Reuptake Inhibitors? Journal of Alzheimer's Disease, 69, 651-661. https://doi.org/10.3233/JAD-180780

[35] Foster, N.A. and Valentine, E.R. (2001) The Effect of Auditory Stimulation on Autobiographical Recall in Dementia. Experimental Aging Research, 27, 215-228. https://doi.org/10.1080/036107301300208664

[36] Irish, M., et al. (2006) Investigating the Enhancing Effect of Music on Autobiographical Memory in Mild Alzheimer's Disease. Dementia and Geriatric Cognitive Disorders, 22, 108-120. https://doi.org/10.1159/000093487

[37] Guzmán-García, A., et al. (2012) Dancing as a Psychosocial Intervention in Care Homes: A Systematic Review of the Literature. International Journal of Geriatric Psychiatry, 28, 914-924. https://doi.org/10.1002/gps.3913

[38] Peck, K.J., Girard, T.A., Russo, F.A. and Fiocco, A.J. (2016) Music and Memory in Alzheimer's Disease and the Potential Underlying Mechanisms. Journal of Alzheimer's Disease, 51, 949-959. https://doi.org/10.3233/JAD-150998

[39] Raglio, A. and Oasi, O. (2015) Music and Health: What Interventions for What Results? Frontiers in Psychology, 6, 230. https://doi.org/10.3389/fpsyg.2015.00230

[40] Cuddy, L.L., et al. (2012) Memory for Melodies and Lyrics in Alzheimer's Disease. Music Perception, 29, 479-491. https://doi.org/10.1525/mp.2012.29.5.479

[41] Platel, H., Baron, J.C., Desgranges, B., Bernard, F. and Eustache, F. (2003) Semantic and Episodic Memory of Music Are Subserved by Distinct Neural Networks. Neuroimage, 20, 244-256. https://doi.org/10.1016/S1053-8119(03)00287-8

[42] Satoh, M., Takeda, K., Nagata, K., Shimosegawa, E. and Kuzuhara, S. (2006) Positron-Emission Tomography of Brain Regions Activated by Recognition of Familiar Music. AJNR, 27, 1101-1106.

[43] Jacobsen, J.H., Stelzer, J., Fritz, T.H., Chételat, G., La Joie, R. and Turner, R. (2015) Why Musical Memory Can Be Preserved in Advanced Alzheimer's Disease. Brain, 138, 2438-2450. https://doi.org/10.1093/brain/awv135

[44] Kongpakwattana, K., Sawangjit, R., Bell, J.S., et al. (2018) Pharmacological Treatments for Alleviating Agitation in Dementia: A Systematic Review and Network Meta-Analysis. British Journal of Clinical Pharmacology, 84, 1445-1456. https://doi.org/10.1111/bcp.13604

[45] Koger, S.M., Chapin, K. and Brotons, M. (1999) Is Music Therapy an Effective Intervention for Dementia? A Meta-Analytic Review of Literature. Journal of Music Therapy, 36, 2-15. https://doi.org/10.1093/jmt/36.1.2

[46] Smith, D.S. (1990) Therapeutic Treatment Effectiveness as Documented in the Gerontology Literature: Implications for Music Therapy. Music Therapy Perspectives, 8, 36-40. https://doi.org/10.1093/mtp/8.1.36

[47] Kneafsey, R. (1997) The Therapeutic Use of Music in a Care of the Elderly Setting: A Literature Review. Journal of Clinical Nursing, 6, 341-346. 
https://doi.org/10.1111/j.1365-2702.1997.tb00326.x

[48] Aldridge, D. (1993) Music Therapy Research 1: A Review of the Medical Research Literature within a General Context of Music Therapy Research. The Arts in Psychotherapy, 20, 11-35. https://doi.org/10.1016/0197-4556(93)90029-2

[49] Biley, F.C. (2000) The Effects of Patient Well-Being of Music Listening as a Nursing Intervention: A Review of the Literature. Journal of Clinical Nursing, 9, 668-677. https://doi.org/10.1046/j.1365-2702.2000.00392.x

[50] Brotons, M., Koger, S.M. and Pickett-Cooper, P. (1997) Music and Dementias: A Review of Literature. Journal of Music Therapy, 34, 204-245. https://doi.org/10.1093/jmt/34.4.204

[51] Koger, S.M. and Brotons, M. (2001) Music Therapy for Dementia Symptoms. The Cochrane Library (Oxford), 4, 1-22.

[52] Lou, M.F. (2001) The Use of Music to Decrease Agitated Behavior of the Demented Elderly: The State of the Science. Scandinavian Journal of Caring Sciences, 15, 165173. https://doi.org/10.1046/j.1471-6712.2001.00021.x

[53] Clair, A.A. (1996) The Effect of Singing on Alert Responses in Persons with Late Stage Dementia. Journal of Music Therapy, 33, 234-247. https://doi.org/10.1093/jmt/33.4.234

[54] Thaut, M.H. (1990) Neuropsychological Processes in Music Perception and Their Relevance in Music Therapy. In: Unkefer, R.F., Ed., Music Therapy in the Treatment of Adults with Mental Disorders. Theoretical Bases and Clinical Interventions, Schirmer Books, New York, 3-32.

[55] Clarke, M.E., Lipe, A.W. and Bilbrey, M. (1998) Use of Music to Decrease Aggressive Behaviors in People with Dementia. Journal of Gerontological Nursing, 24, 10-17. https://doi.org/10.3928/0098-9134-19980701-05

[56] Thomas, D.W., Heitman, R.J. and Alexander, T. (1997) The Effects of Music on Bathing Co-Operation for Residents with Dementia. Journal of Music Therapy, 34, 246-259. https://doi.org/10.1093/jmt/34.4.246

[57] Brotons, M. and Pickett-Cooper, P.K. (1996) The Effects of Music Therapy Intervention on Agitation Behaviours of Alzheimer's Disease Patients. Journal of Music Therapy, 33, 2-18. https://doi.org/10.1093/jmt/33.1.2

[58] Denney, A. (1997) Quiet Music: An Intervention for Mealtime Agitation? Journal of Gerontological Nursing, 23, 16-23. https://doi.org/10.3928/0098-9134-19970701-09

[59] Gerdner, L.A. and Swanson, E.A. (1993) Effects of Individualized Music on Confused and Agitated Elderly Patients. Archives of Psychiatric Nursing, 7, 284-291. https://doi.org/10.1016/0883-9417(93)90006-I

[60] Gerdner, L.A. (2000) Effects of "Individualized" versus "Relaxation" Music on the Frequency of Agitation in Elderly Persons with Alzheimer's Disease and Related Disorders. International Psychogeriatrics, 12, 49-65. https://doi.org/10.1017/S1041610200006190

[61] Goddaer, J. and Abraham, I.L. (1994) Effects of Relaxing Music on Agitation during Meals among Nursing Home Residents with Severe Cognitive Impairment. Archives of Psychiatric Nursing, 8, 150-158. https://doi.org/10.1016/0883-9417(94)90048-5

[62] Tabloski, P.A., Mckinnon-Howe, L. and Remington, R. (1995) Effects of Calming Music on the Level of Agitation in Cognitively Impaired Nursing Home Residents. The American Journal of Alzheimer's Care and Related Disorders \& Research, 10, 10-15. https://doi.org/10.1177/153331759501000105 
[63] Groene, R.W. (1993) Effectiveness of Music Therapy 1:1 Intervention with Individuals Having Senile Dementia of the Alzheimer's Type. Journal of Music Therapy, 30, 138-157. https://doi.org/10.1093/jmt/30.3.138

[64] Casby, J.A. and Holm, M.B. (1994) The Effect of Music on Repetitive Disruptive Vocalizations of Persons with Dementia. American Journal of Occupational Therapy, 48, 883-889. https://doi.org/10.5014/ajot.48.10.883

[65] Ragneskog, H., Brane, G., Karlsoon, I. and Kihlgren, M. (1996) Influence of Dinner Music on Food Intake and Symptoms Common in Dementia. Scandinavian Journal of Caring Sciences, 10, 11-17. https://doi.org/10.1111/j.1471-6712.1996.tb00304.x

[66] Gomez, G.M. and Gomez, G.J. (2017) Music Therapy and Alzheimer's Disease: Cognitive, Psychological, and Behavioral Effects. Neurología, 32, 300-308. https://doi.org/10.1016/j.nrleng.2015.12.001

[67] Sakamoto, M., Ando, H. and Tsutou, A. (2013) Comparing the Effects of Different Individualized Music Interventions for Elderly Individuals with Severe Dementia. International Psychogeriatrics, 25, 775-784. https://doi.org/10.1017/S1041610212002256

[68] Smith-Marchese, K. (1994) The Effects of Participatory Music on the Reality, Orientation and Sociability of Alzheimer's Residents in a Long-Term Care Setting. Activities, Adaptation and Aging, 18, 41-55. https://doi.org/10.1300/J016v18n02 04

[69] Lord, T.R. and Garner, J.E. (1993) Effects of Music on Alzheimer Patients. Perceptual and Motor Skills, 76, 451-455. https://doi.org/10.2466/pms.1993.76.2.451

[70] Ragneskog, H., Kihlgren, M., Karlsoon, I. and Norberg, A. (1996) Dinner Music for Demented Patients: Analysis of Video Recorded Observations. Clinical Nursing Research, 5, 262-282. https://doi.org/10.1177/105477389600500302

[71] Clair, A.A., Bernstein, B. and Johnson, G. (1995) Rhythm Playing Characteristics in Persons with Severe Dementia Including Those with Probable Alzheimer's Type. Journal of Music Therapy, 32, 113-131. https://doi.org/10.1093/jmt/32.2.113

[72] Olderog-Millard, K.A. and Smith, J.M. (1989) The Influence of Group Singing Therapy on the Behavior of Alzheimer's Disease Patients. Journal of Music Therapy, 26, 58-70. https://doi.org/10.1093/jmt/26.2.58

[73] Pollack, N. and Namazi, K.H. (1992) The Effect of Music Participation on the Social Behavior of Alzheimer's Disease Patients. Journal of Music Therapy, 29, 54-67.

https://doi.org/10.1093/jmt/29.1.54

[74] Snyder, M. and Olson, J. (1996) Music and Hand Massage Interventions to Produce Relaxation and Reduce Aggressive Behaviors in Cognitively Impaired Elders: A Pilot Study. Clinical Gerontologist, 17, 64-69.

[75] Clair, A.A. and Bernstein, B. (1994) The Effect of No Music, Simulative Background Music and Sedative Background Music on Agitated Behaviors in Persons with Severe Dementia. Activities, Adaptation and Aging, 19, 61-70. https://doi.org/10.1300/J016v19n01 05

[76] Brotons, M. and Marti, P. (2003) Music Therapy with Alzheimer's Patients and Their Family Caregivers: A Pilot Project. Journal of Music Therapy, 40, 138-150. https://doi.org/10.1093/jmt/40.2.138

[77] Leggieri, M., Thaut, M.H., Fornazzari, L., et al. (2019) Music Intervention Approaches for Alzheimer's Disease: A Review of the Literature. Frontiers in Neuroscience, 12, 130-132. https://doi.org/10.3389/fnins.2019.00132

[78] Kolsch, S. (2009) A Neuroscientific Perspective on Music Therapy. The Neuros- 
ciences and Music III Disorders and Plasticity: Annals of the New York Academy of Sciences, 1169, 374-384. https://doi.org/10.1111/j.1749-6632.2009.04592.x

[79] Kobets, A.J. (2011) Harmonic Medicine: The Influence of Music over Mind and Medical Practice. Yale Journal of Biology and Medicine, 84, 161-167. 